\title{
Anti-neuroinflammatory activity of Humulus japonicus extract and its active compound luteolin on lipopolysaccharide-induced inflammatory response in SIM-A9 microglia via NF- $\kappa B$ and MAPK signaling pathways
}

\author{
Feng WANG ${ }^{1,2}$, Byoung Ok CHO ${ }^{3,4}$, Jae Young $\mathrm{SHIN}^{1,4}$, Suping $\mathrm{HAO}^{1}$, Seon Il JANG ${ }^{1,3,4 \star}$
}

\begin{abstract}
Humulus japonicus $(\mathrm{HJ})$ is administered to patients with pulmonary disease and skin disease owing to its anti-inflammatory and antioxidant effects. Lately, $\mathrm{HJ}$ has been shown to exert impacts on protection against neurodegenerative sickness. Nevertheless, its impacts on microglia have not been discovered in depth. As a result, anti-inflammatory impacts of HJ ethanol extract (HJE) and its active compound luteolin on lipopolysaccharide-stimulated SIM-A9 cells were investigated. The results showed that HJE luteolin inhibited generation of interleukin- $1 \beta$, tumor necrosis factor- $\alpha$, nitric oxide, interleukin- 6 , together with prostaglandin $\mathrm{E}_{2}$, iNOS, COX-2 along with HO-1 induction. Furthermore, HJE and luteolin reduced degrees of NF- $\mathrm{kB}$ pathway components within cytoplasm and nucleus, while reducing cytoplasmic MAPK levels and increasing Nrf2 levels in the cytoplasm and nucleus. In conclusion, our results demonstrate that HJE might exhibit neuroprotective effects and could be used as a novel drug for various neurological diseases.
\end{abstract}

Keywords: Humulus japonicus; anti-neuroinflammation; NF-кB; MAPK; microglia.

Practical Application: HJE can be used as a source of natural products in the functional food or pharmaceutical industry.

\section{Introduction}

Innate immunity is cured via microglial cells in CNS, which are resident cells responsible for adjusting inflammation within CNS to fight insults outside and inside CNS. Microglial cells are acquired from erythro-myeloid progenitors located in yolk sac in the forepart of embryonic process and they make proliferation continuously; thus, maintaining a steady population throughout life (Askew et al. 2017; Hoeffel et al., 2015). Under normal physiological conditions, microglial cells counteract overall disorders in immunological homeostasis in order to enhance neural precursor cell proliferation along with survival, a phenomenon that protects neurons that have minor influence on regeneration. In the environment of pathologic, the activation of microglial cells are completed and they have significant influence in the development of neurodegenerative sickness covering amyotrophic lateral sclerosis, Alzheimer's disease, multiple sclerosis, Parkinson's disease along with prioninduced neurodegeneration (Perry et al., 2010). In their naïve state or upon interacting with else incoming immune cells (working as antigen-presenting cells), microglia make the release of many inflammatory intermediaries covering interleukin-6, nitric oxide, interleukin- $1 \beta$, prostaglandin $\mathrm{E}_{2}$ together with reactive oxygen and nitrogen species which cause neurotoxicity. Thus, modulation of microglial activation, neuroinflammation, and oxidative stress generated as the result of reduced free radical accumulation might indicate a therapeutic strategy for neurodegenerative diseases.

Humulus japonicus Siebold \& Zucc (HJ) is an annual medicinal herb from the Cannabaceae family (Park et al., 1994). HJ is cognized as hop from Japan in wide range and is widespread in temperate Asia covering the Republic of Korea, Japan as well as Taiwan. People in the Republic of Korea adopt this herb to treat pulmonary tuberculosis and hypertension (Yu et al., 2007). It exerts numerous beneficial properties covering anti-aging, anti-inflammatory along with antioxidant impacts, which could result from presence of polyphenols (Choi et al., 2018; Sung et al., 2015; Yu et al., 2007). The protective effects of 100\% methanolic $\mathrm{HJ}$ extracts have been demonstrated in Alzheimer's disease model in mice (Park et al., 2017), while those of 100\% methanolic and ethanolic $\mathrm{HJ}$ extracts have been demonstrated in 6-hydroxydopamine-induced Parkinson's sickness models (Lee et al., 2019; Ryu et al., 2017) and in antiaging yeast models (Sung et al., 2015). HJ was found to exert anti-inflammatory effects in the context of neurodegenerative diseases. However, anti-inflammatory effects along with mechanism of $\mathrm{HJ}$ extract action have been rarely reported.

Thus, in this work, we discovered anti-inflammatory impacts of the HJ extracts in lipopolysaccharide (LPS)-stimulated microglia cells by evaluating the levels of proinflammatory intermediaries, 
for example, NO, PGE, iNOS along with COX2, and cytokines, for example, IL-6, IL-1 $\beta$, TNF- $\alpha$ along with HO-1. Furthermore, role of $\mathrm{HJ}$ extract in the control of NF- $\mathrm{KB} / \mathrm{MAPK} / \mathrm{Nrf} 2$ signaling pathways was explored.

\section{Materials and methods}

\subsection{Reagents}

SIM-A9 microglial cells (CRL-3265) were obtained from ATCC (Manassas, VA, USA). The EZ-Cytox reagent assay kit along with EZ-western Lumi Pico Alpha was provided by DoGenBio (Seoul, South Korea). DMEM supplemented by the odium pyruvate $(110 \mathrm{mg} / \mathrm{mL})$, FBS, and HS was procured from Gibco (Gibco, Grand Island, NY, USA). We bought Penicillin together with streptomycin from Invitrogen (Invitrogen, Carlsbad, CA, USA) and bought SDS-PAGE loading buffer from Biosesang (Seongnam, South Korea) and polyvinylidene fluoride membranes from Millipore (MA, USA). Luteolin (purity $>98 \%$ ), DMSO and LPS from Escherichia coli O111:B4, Trypan Blue, Greiss reagent (modified), protease along with phosphatase inhibitors were porcured from Sigma-Aldrich (St. Louis, MO, USA). We acquired the RIPA buffer and NE-PER nuclear together with the extraction reagents of cytoplasm from Thermo Scientific (Rockford, IL, USA). The Bio-Rad Protein Assay was procured from Bio-Rad (Hercules, CA, USA). Phospho-Akt, Akt, lamin b antibodies were procured from Cell Signaling Technology Inc.

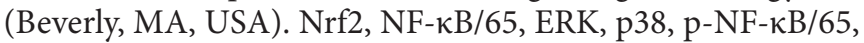
p-JNK, JNK, p-p38, p-ERK, HO-1, primary antibodies, as well as the secondary antibodies combined with HRP-IgG, which we bought from Santa Cruz Biotechnoogy (Santa Cruz, CA, USA). We obtained actin antibody from Biosciences (Franklin Lakes, NJ, USA) and bought IL-1 $\beta$, TNF- $\alpha$, IL- 6 , along with $\mathrm{PEG}_{2}$ ELISA kits from R\&D Systems (Minneapolis, MN, USA).

\subsection{HJ ethanol extracts (HJE)}

We obtained HJ leaves from Cheonjam Hill, Wansan-Gu, Jeoju-shi, Jeonbuk, Korea on June 25, 2020. Professor Hong-Jun Kim from College of Oriental Medicine, Woosuk University identified and authenticated above-mentioned plant (Wanju, Korea). Our lab stored a voucher specimen (\#2020-06-25-HJ). We washed these leaves by distilled water and make them dried under the temperature of $60^{\circ} \mathrm{Clasting}$ sixteen hours, and incubated $(50 \mathrm{~g})$ with $80 \%(\mathrm{v} / \mathrm{v})$ ethanol (two thousand $\mathrm{mL}$ ) lasting $48 \mathrm{~h}$ at $40{ }^{\circ} \mathrm{C}$ in a water bath. We utilized a filter paper to filter the extract through a $0.45 \mathrm{~mm}$ pore size (ADVANTEC, Togo, Japan). After filtering extract was vacuum concentrated at $45^{\circ} \mathrm{C}$ along with ethanol being removed. Residual solution was freeze-dried in a freeze dryer at $-55^{\circ} \mathrm{C}$ for acquiring dry powder and kept under the environment of $-20^{\circ} \mathrm{C}$ for subsequent research.

\subsection{Cell incubation conditions}

We adopted DMEM solution to culture and keep Microglial cells (SIM-A9) and the above-mentioned solution was supplemented with fetal bovine serum of ten percent, $5 \%$ horse serum, $1 \mathrm{~mL}$ penicillin together with one hundred $\mu \mathrm{g} / \mathrm{mL}$ streptomycin antibiotics under the temperature of $37^{\circ} \mathrm{C}$ in an atmosphere of five percent $\mathrm{CO}_{2}$. Cells were maintained in $90 \times 20 \mathrm{~mm}$ cell culture dishes and $80 \%$ confluent culture dishes were used for the following research. The cells were not serum-starved in any of our research.

\subsection{Cell viability}

We adopted EZ-Cytox reagent to figure out cell viability. $3 \times 10^{5}$ cells $/ \mathrm{mL}$ of SIM-A9 cells were inoculated into 96-well plates and cultivated lasting sixteen hours and disposed by HJE or LPS for $20 \mathrm{~h}$. We added EZ-Cytox reagent $(0.01 \mathrm{~mL})$ into each well and cultivated lasting four hours. Trough measuring the absorbance at $450 \mathrm{~nm}$, we could observe cell viability with the assistance of a microplate reader (Tecan, Männedorf, Switzerland). We could make a comparison of optical density of viable cells vs that of untreated controls in order to figure out cell viability.

\subsection{NO generation}

We cultivated Microglial cells $\left(5 \times 10^{5}\right.$ cells $\left./ \mathrm{mL}\right)$ in 6-well dishes lasting sixteen hours and disposed by HJEs concentrated of 0,25 , or $50 \mu \mathrm{g} / \mathrm{mL}$ and $30 \mu \mathrm{M}$ luteolin lasting one hour. After that, we stimulated the cells by $2 \mu \mathrm{g} / \mathrm{mL}$ of LPS lasting twentyfour hours. There was NO secretion measurement through Griess approach. Shortly, we added $0.1 \mathrm{~mL}$ of a culture media supernatant into $0.1 \mathrm{~mL}$ of Griess reagent and cultivated lasting fifteen minutes under the temperature of $20^{\circ} \mathrm{C}$. Subsequently, we made the measurement of absorbance at $540 \mathrm{~nm}$. Observing from a sodium nitrite standard curve which came from this work, the concentration of NO was formed.

\subsection{ELISA}

Microglial cells $\left(5 \times 10^{5}\right.$ cells $\left./ \mathrm{mL}\right)$ were inoculated into 6 -well cell culture dish lasting sixteen hours and disposed by 0 , 25 , or $50 \mu \mathrm{g} / \mathrm{mL} \mathrm{HJE}$ and luteolin $(30 \mu \mathrm{M})$ for $1 \mathrm{~h}$ in advance. Subsequently, we stimulated the cells by $2 \mu \mathrm{g} / \mathrm{mL}$ LPS lasting twenty-four hours. We made the collection of culture media and measured the production of TNF- $\alpha$, PGE $_{2}$ IL- $1 \beta$, IL- 6 in the supernatants by ELISA kits as per the manufacturer's instructions.

\subsection{Whole protein extraction and western blotting}

Microglial cells $\left(5 \times 10^{5}\right.$ cells $\left./ \mathrm{mL}\right)$ were seeded in $90 \times 20 \mathrm{~mm}$ cell culture dish lasing sixteen hours, and treated with 0,25 , or $50 \mu \mathrm{g} / \mathrm{mL} \mathrm{HJE}$ and $30 \mu \mathrm{M}$ luteolin for $1 \mathrm{~h}$, after stimulating the cells by LPS $(2 \mu \mathrm{g} / \mathrm{mL})$ for $0.5 \mathrm{~h}$ or $24 \mathrm{~h}$. Then, whole cell lysates corresponding to each treatment were prepared in RIPA buffer added with phosphatase and protease inhibitors and subsequently centrifuged at $12,000 \times g$ lasting fifteen minutes under the temperature of $4{ }^{\circ} \mathrm{C}$ to acquire supernatant covering entire protein extract. Following protein quantification with Bio-Rad protein assay, protein from each sample was resolved on an $10 \%$ or twelve percent SDS-PAGE (110 V lasting 1.5 hour). Following separation, we moved the proteins onto polyvinylidene fluoride membranes (100 V lasting one hour). we placed membranes under block in five percent bovine serum albumin lasting one hour and then cultivated the whole night under the temperature of $4{ }^{\circ} \mathrm{C}$ by various antibodies (JNK, p-p38, p-ERK, ERK, Nrf2, iNOS, p-JNK, Cox-2, p38, HO- 1 , and $\beta$-actin). Later than this 
step, we washed the membranes three times with TBST ( 5 minutes for every wash) and then cultivated by related HRP-conjugated secondary antibodies lasting two hours under the temperature of $20^{\circ} \mathrm{C}$. After that, we washed membranes five times with TBST (5 minutes for every wash) and adopted EZ-western Lumi Pico Alpha chemiluminescence reagent to make them visualized on an imaging system (Alliance version 15.11; UVITEC Cambridge, UK). We utilized tripping buffer as well to make various proteins to be visualized on a sole membrane. The adoption of ImageJ version 1.52 (US National Institute of Health, Bethesda, MD, USA) could benefit determining band densities. For the sake of confirming protein loading with the same quantity, membranes were stripped and results with anti $\beta$-actin antibodies utilizing the above-mentioned protocol.

\subsection{Cytosol and nuclear protein extraction and western blotting}

Microglial cells $\left(5 \times 10^{5}\right.$ cells $\left./ \mathrm{mL}\right)$ were inoculated into $90 \times 20 \mathrm{~mm}$ dishes lasting sixteen hours, after that being disposed by 0,25 , or $50 \mu \mathrm{g} / \mathrm{mL} \mathrm{HJE}$ and $30 \mu \mathrm{M}$ luteolin lasting one hour, later than stimulating cells with LPS $(2 \mu \mathrm{g} / \mathrm{mL})$ lasting 0.5 hour. Then, nuclear along with cytoplasm proteins were extracted from cells in each treatment condition through NE-PERTM nuclear and cytoplasmic extraction reagent conforming to the producer's instructions. Shortly, we cultivated cells by suspension in ice-cold DPBS and centrifuged at $500 \times$ g lasting three minutes under the temperature of $4{ }^{\circ} \mathrm{C}$ to acquire cell pellets. Then we removed DPBS and added the reagent of ice-cold CER I $(0.1 \mathrm{~mL})$. Then, vigorously vortexed and cultivated on ice lasting ten minutes, we supplemented $0.0055 \mathrm{~mL}$ of CER II reagent and the resultant suspension vortexed, and cultivated on ice lasting one minute. After that, cell suspensions were centrifuged at $14000 \times g$ lasting fifteen minutes, while supernatant including cytoplasmic proteins was at once moved into new tubes and kept under the temperature of $-80^{\circ} \mathrm{C}$. Insoluble fraction acquired following centrifugation was resuspended in $0.05 \mathrm{~mL}$ ice-cold NER reagent covering phosphatase and protease inhibitors, and vortexed every ten minutes for a total of forty minutes corresponding with icy incubation. Then, centrifuged at $14000 \times g$ lasting ten minutes, while supernatant covering nuclear extracts was moved to pre-chilled new tubes at once and kept under the temperature of $-80^{\circ} \mathrm{C}$ for the following studies. Protein quantification and western blotting, which was conducted according to previous description. But, at this moment, membranes were cultivated with Akt, p-Akt, lamin b, NF-kB, Nrf2, $\beta$-actin, or $\mathrm{p}$-NF- $\kappa \mathrm{B}$ antibodies.

\subsection{Statistical analysis}

Data are expressed with mean \pm standard deviation. We suppose the significant difference when the p-value was lower than 0.05 . Two-sample comparisons were carried out through Student's $t$-test.

\section{Results and discussion}

\subsection{Toxicity of HJE and luteolin toward microglial cells}

We recognize LPS as a basic element of gram-negative bacteria and a strong stimulator of microglial activation and we usually adopted LPS for neuroinflammatory study (Xu et al., 2018). The EZ-Cytox reagent was carried out cell viability. HJE treatment $(0,12.5,25,50,100,200$, along with $400 \mu \mathrm{g} / \mathrm{mL})$ and luteolin treatment $(0,5,10,20,40,60$, and $80 \mu \mathrm{M})$, rare significant cytotoxicity was noticed up to a concentration of $100 \mu \mathrm{g} / \mathrm{mL}$ of HJE (Figure 1A) and $80 \mu \mathrm{M}$ of Luteolin (Figure 1C). Co-treatment with HJE (up to $100 \mu \mathrm{g} / \mathrm{mL}$ ) along with LPS $(2 \mu \mathrm{g} / \mathrm{mL})$ (Figure 1B), co-treatment with luteolin (up to $60 \mu \mathrm{M}$ ) and LPS $(2 \mu \mathrm{g} / \mathrm{mL})$ (Figure 1D) had no linkage with cytotoxicity. From above results, 25 and $50 \mu \mathrm{g} / \mathrm{mL}$ of $\mathrm{HJE}, 30 \mu \mathrm{M}$ of luteolin were prepared for next research.

\subsection{Impacts of HJE and luteolin on pro-inflammatory cytokines (IL-1 $\beta, T N F-\alpha, I L-6)$ and pro-inflammatory intermediaries (NO, iNOS, PGE ${ }_{2}$, COX2)}

Microglia play a primary role in protecting Central Nervous System, thereby representing the first line of defense, and serving as initiators of immune responses against injuries and stimuli (Stephenson et al., 2018). Strangely activated microglia generate various pro-inflammatory intermediaries (ROS, COX2, $\mathrm{PGE}_{2}$, NO, iNOS) and cytokines (IL- $1 \beta$, TNF- $\alpha$, and IL-6) (Yang et al., 2020). In addition, neuroinflammatory responses in the Central Nervous System are strongly correlated with neurological sickness, for example, Parkinson's Diseases and Alzheimer's Diseases, inducing neuronal death, synaptic degeneration together with cognitive impairment (Perry et al., 2010). As a result, control of the neuroinflammatory response represents a significant therapeutic tactics for neurological sickness.

If we stimulate microglia through activators like LPS, it will generate neurotoxic pro-inflammatory intermediaries, leading to the vanishment of nearby neurons (Onasanwo et al., 2016). Immoderate $\mathrm{NO}$ analysis by activated microglia results in reactive nitrogen species formation and neuronal death (Yuste et al., 2015). $\mathrm{PGE}_{2}$ which origins from overactivated microglia was supposed to induce neuronal death through activating the EP2 receptors (Miyagishi et al., 2013). Pro-inflammatory cytokines like TNF- $\alpha$, IL-1 $\beta$, IL-6 along with other intermediaries containing reactive oxygen species, are thought to take part in mediating neuronal vanishment and exacerbation of neurodegenerative sickness (Block \& Hong, 2005). Our data showed when stimulated by only LPS, NO, iNOS, and PEG, COX2 significantly increased (Figure 2) together with IL-1 $\beta$, TNF- $\alpha$, IL-6 also signifyingly increased (Figure 3). However, when pretreated with HJE and luteolin before stimulated by LPS, NO, iNOS, and PEG COX2 significantly decreased (Figure 2), as well as TNF- $\alpha$, IL-6, and IL-1 $\beta$ also signifyingly decreased (Figure 3 ). The results showed HJE and luteolin significantly inhibited pro-inflammatory cytokines expression (IL-1 $\beta$, TNF- $\alpha$, IL-6) (Figure3) and proinflammatory intermediaries (NO, iNOS, COX2 along with $\mathrm{PGE}_{2}$ ) (Figure 2) in LPS-activated SIM-A9 microglial cells.

\subsection{Impacts of HJE and luteolin on the NF- $\mathrm{B} B, A K T$, and MAPK pathway in stimulated microglia}

There have been some studies indicating that LPS-activated microglia exhibit pro-inflammatory reactions through different signaling pathways that prompt sickness development in 
A

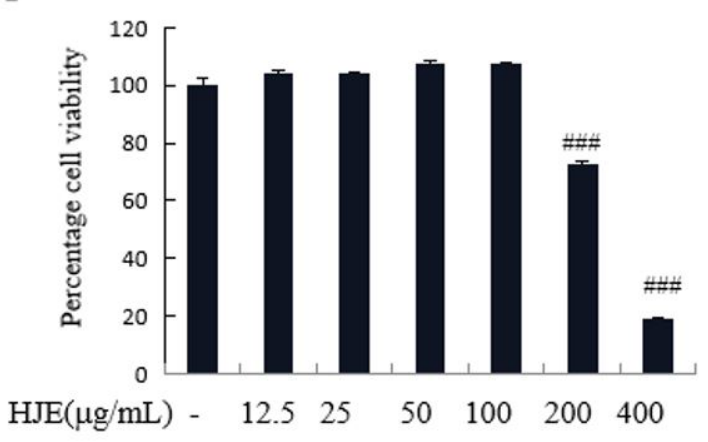

$\mathrm{C}$

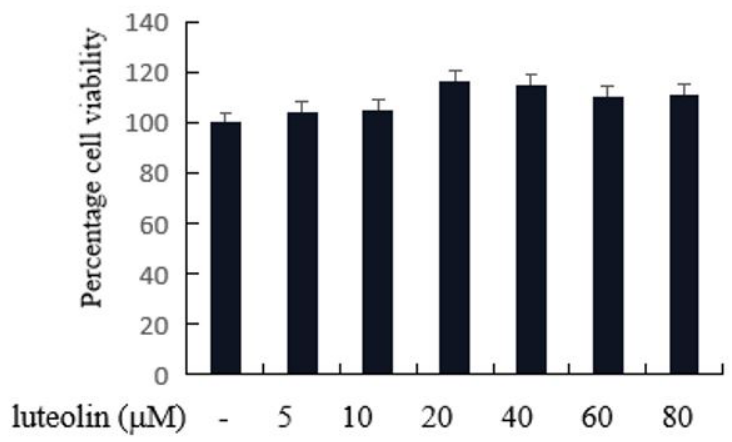

B

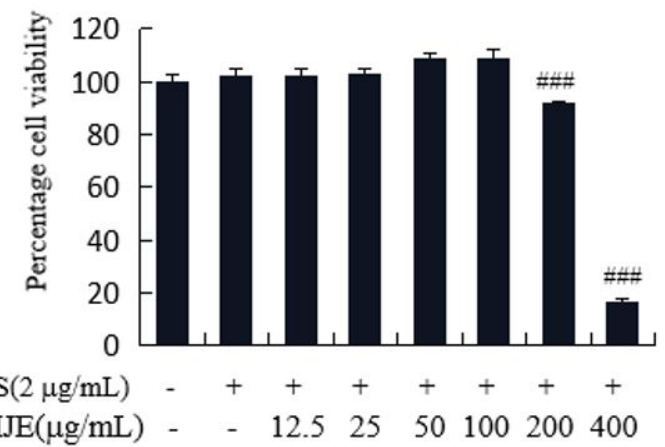

$\mathrm{D}$

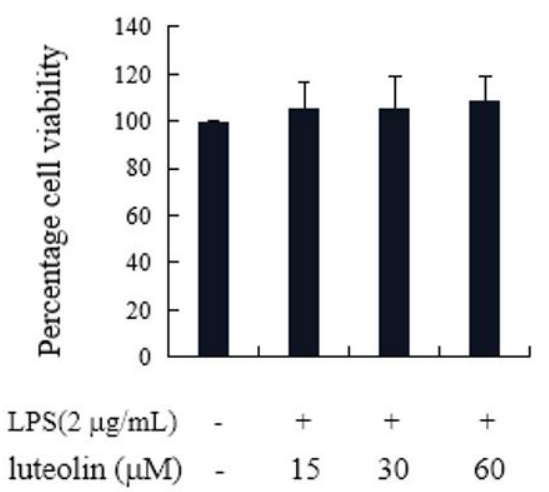

Figure 1. The cell viability of Humulus japonicus extract (HJE) and Luteolin toward microglial cells. Microglial cells $\left(5 \times 10^{5}\right.$ cells $\left./ \mathrm{mL}\right)$ were cultivated and disposed by HJE solely at mentioned concentrations (A), HJE at the indicated concentrations and disposed $2 \mu \mathrm{g} / \mathrm{mL}$ LPS (B), Luteolin alone at indicated concentrations (C), and Luteolin at $0,15,30$, or $60 \mu \mathrm{M}$ and treated $2 \mu \mathrm{g} / \mathrm{mL}$ LPS (D) lasting twenty-four hours before cell viability research conduction. Outcomes are displayed with the mean \pm standard deviation $(\mathrm{n}=3)$. ${ }^{\# \#} \mathrm{P}<.001$ versus the control group.

neurodegeneration models (Fellner et al., 2017; Subedi et al., 2017). The transcription element NF- $\kappa$ B controls various ways of innate and adaptive immune systems and acts as crucial intermediaries of inflammatory replies. Different pro-inflammatory genes' expression results from NF- $\kappa \mathrm{B}$ covering encoding cytokines and chemokines, and takes part in inflammasome control. Besides, NF- $\kappa \mathrm{B}$ possesses significant effect on controlling the survival, differentiation and activation of inflammatory $\mathrm{T}$ cells and innate immune cells. As a result, NF- $\kappa \mathrm{B}$ activation which out of control induces pathogenesis of different inflammatory sickness (Liu et al., 2017). Only LPS disposal lasting thirty minutes benefited NF- $\mathrm{B} / \mathrm{p} 65$ phosphorylation of observed from Figure 4A. But if cells were disposed by HJE or luteolin in advance, these cells demonstrated distinct decrease in $\mathrm{p}-\mathrm{NF}-\kappa \mathrm{B} /$ p65 expression. As shown in Figure 4B, stimulating microglial cells by LPS alone lasting thirty minutes obviously contributed to $\mathrm{p}-\mathrm{NF}-\kappa \mathrm{B} / \mathrm{p} 65$ translocation. Nevertheless, when the cells were pre-treated through luteolin or HJE, p-NF- $\kappa \mathrm{B} / \mathrm{p} 65$ expression in the nuclear extracts was obviously reduced.

During neuroinflammation, NF- $\kappa \mathrm{B}$ activation regulates pro-inflammatory intermediaries' generation like $\mathrm{NO}$ together with its mediator protein iNOS as well as $\mathrm{PGE}_{2}$ and its mediator protein COX2, TNF- $\alpha$, ROS, cytokines IL-6 (Onasanwo et al., 2016). Our studies revealed that $\mathrm{HJE}$ and luteolin treatment downregulated NF- $\kappa \mathrm{B}$ phosphorylation, thus, reducing the degrees of pro-inflammatory intermediaries and cytokines.

It was advised that BV2 microglial cells were activated by LPS through MAPK/ERK pathway. In BV2 cells, LPS raised pro-inflammatory factors generation such as TNF-a, NO, along with iNOS (M1 phenotypic marker), and reduced antiinflammatory factors generation such as IL-10 together with CD206 (M2 phenotypic marker), coupled with phosphorylation of ERK1/2. Besides, cumulative demonstration confirms that various protein kinases covering mitogen activated phosphatidylinositol3-kinase (PI3K)/Akt and protein kinases (MAPKs), have the linkage of phosphorylation and nuclear accumulation of Nrf2 (Joshi \& Johnson, 2012; Bryan et al., 2013).

Our data showed that when the cells were treated with in only LPS-stimulated SIM A9 microglial cells, AKT (Figure 4C) and MAPK (Figure 5) increased significantly, but after HJE and Luteolin pretreatment, AKT (Figure 4C) and MAPK (Figure 5) decreased significantly, as well as significantly decreased the levels of phosphorylated NF- $\kappa$ B (Figure $4 \mathrm{~A}, 4 \mathrm{~B}$ ), which downregulate various inflammatory mediators' generation covering IL- $1 \beta$, 
A

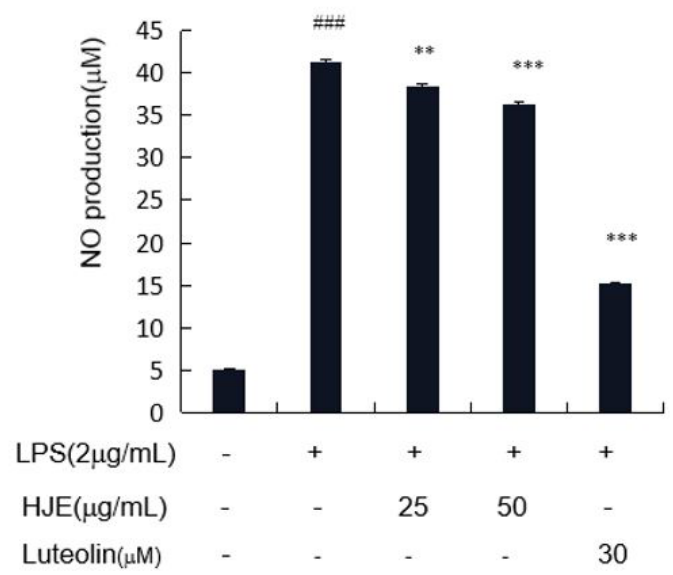

$\mathrm{C}$

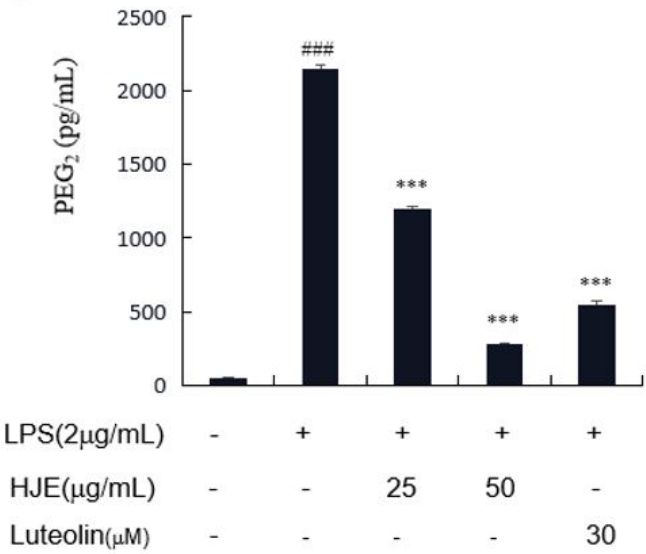

B

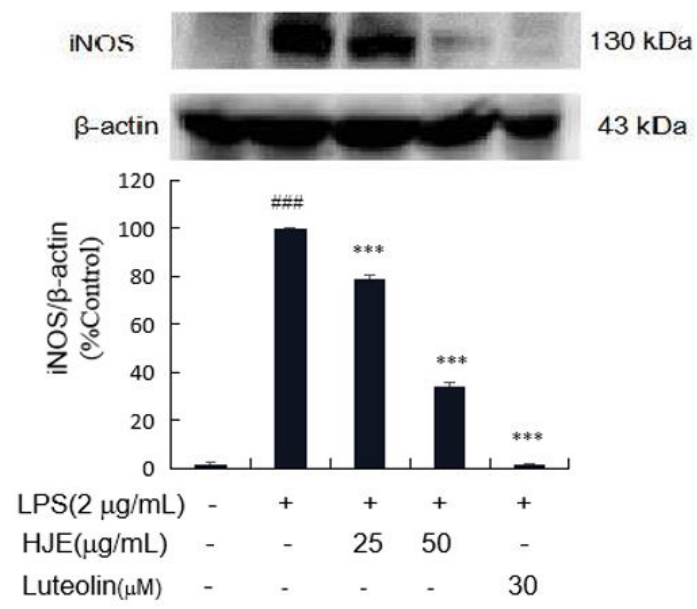

D

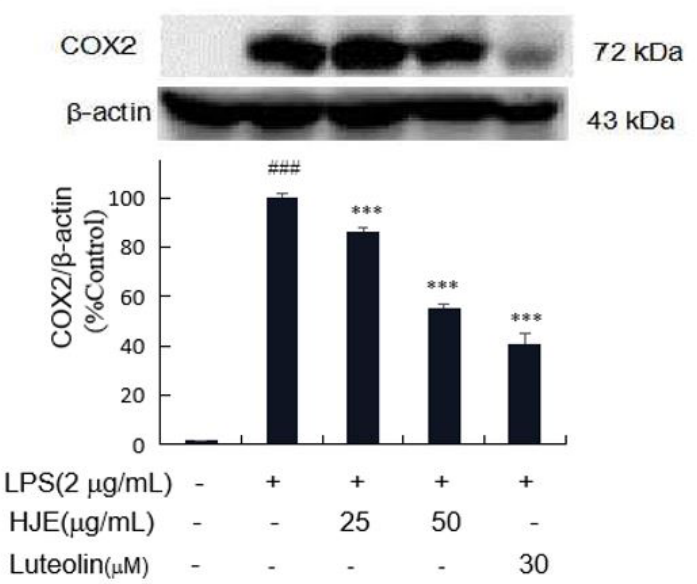

Figure 2. The effects of HJE and luteolin NO production (A), iNOS expression levels (B), $\mathrm{PGE}_{2}$ generation (C), and COX2 expression degrees (D) in LPS-stimulated microglia cells. Microglial cells were disposed by HJE (25 or $50 \mu \mathrm{g} / \mathrm{mL})$, Luteolin $(30 \mu \mathrm{M})$ lasting one hour,after that stimulated with LPS $(2 \mu \mathrm{g} / \mathrm{mL})$ lasting twenty-four hours. The measurement of $\mathrm{NO}$ and $\mathrm{PGE}_{2}$ production degrees in cell culture supernatants was conducted through Griess assay kit and ELISA kit. The iNOS and COX2 expression degrees were discovered through western blot analysis of whole-cell protein extract. Error bars stand for means $\pm \mathrm{SD} ;{ }^{\# * *} \mathrm{P}<.001$ versus the control group; ${ }^{* *} \mathrm{P}<.01,{ }^{* *} \mathrm{P}<.001$ versus only LPS team. Results from three researches of independence are symbolic.

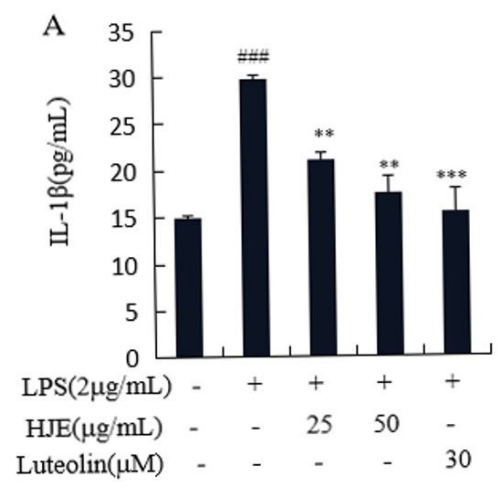

B

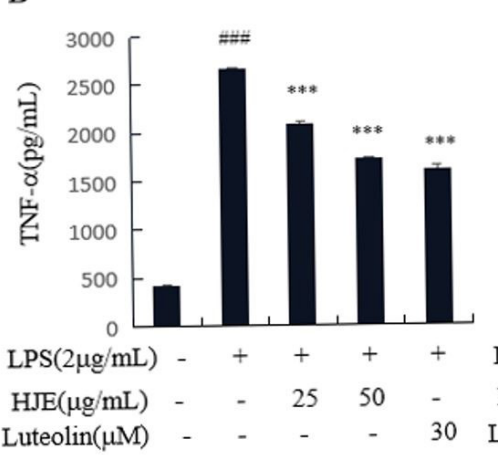

C

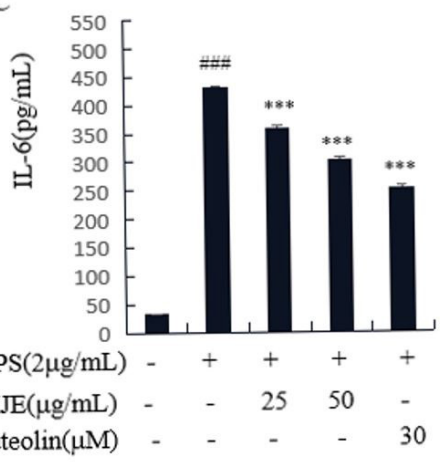

Figure 3. Impacts of HJE and luteolin on IL-1 $\beta(A)$, TNF- $\alpha(B)$ along with IL-6 (C) production in the microglial cells stimulated by LPS. Cells were pretreated with HJE $(25$ or $50 \mu \mathrm{g} / \mathrm{mL})$, Luteolin $(30 \mu \mathrm{M})$ and stimulated with LPS $(2 \mu \mathrm{g} / \mathrm{mL})$. Microglial cells were disposed by HJE $(25$ or $50 \mu \mathrm{g} / \mathrm{mL})$, Luteolin $(30 \mu \mathrm{M})$ lasting $1 \mathrm{~h}$, and subsequently stimulated through $2 \mu \mathrm{g} / \mathrm{mL}$ LPS for one day. We made the collection of culture media supernatants and utilized for ELISA. Error bars stand for means $\pm \mathrm{SD} ;{ }^{* * *} \mathrm{P}<.001$ versus the control group; ${ }^{* *} \mathrm{P}<.01$, and ${ }^{* * *} \mathrm{P}<.001$ versus only LPS team. Outcomes from three researches of independence are symbolic. 

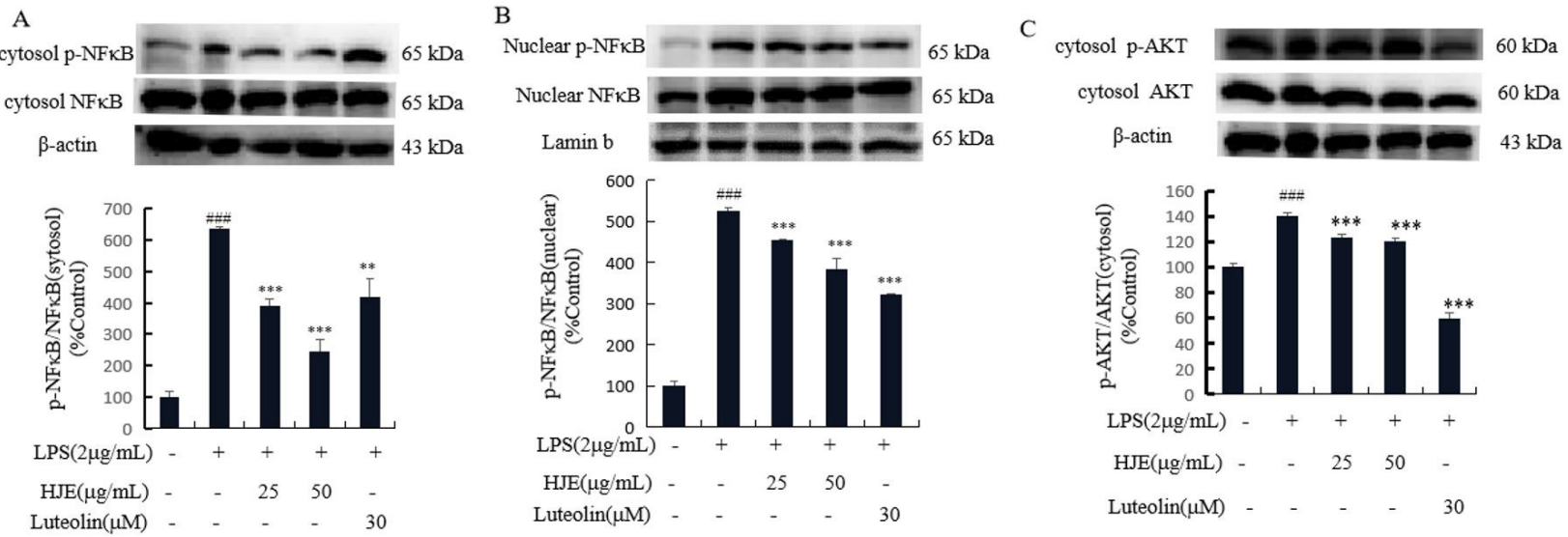

Figure 4. HJE and luteolin regulate the activation of NF- $\kappa B$ signal pathways (A), inhibited the nuclear translocation of NF- $\kappa \mathrm{B}(\mathrm{B})$, on $\mathrm{AKT}$ expression levels (C)in the microglial cells induced by LPS. Microglial cells $\left(5 \times 10^{5} \mathrm{cells} / \mathrm{mL}\right)$ were cultivated and disposed by HJE or luteolin in advance and then stimulated with LPS lasting thirty minutes. The protein expression degrees of cell signaling kinases along with activated NF- $\kappa \mathrm{B}$ from nuclear extract and AKT were discovered through western blot assays and the analysis of band densities was conducted with the assistance of ImageJ analysis software and normalized to $\beta$-actin and Lamin b degrees. Error bars represent the means \pm SD; ${ }^{\# \# \# ~}<.001$ versus control team; ${ }^{* *} \mathrm{P}<.01$, and ${ }^{* * *} \mathrm{P}<.001$ versus only LPS team. Outcomes from three researches of independence are symbolic.

A

\section{p-ERK1/2 \\ ERK1/2}

$\beta$-actin

p-JNK

JNK

$\beta$-actin

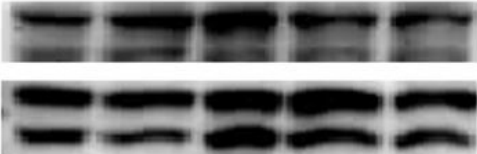

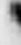

p-P38

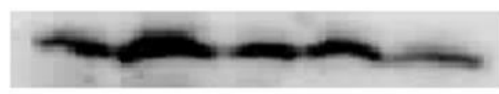

P38

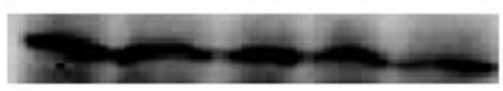

$\beta$-actin
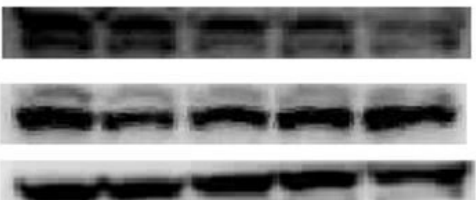

oat wos

$43 \mathrm{kDa}$
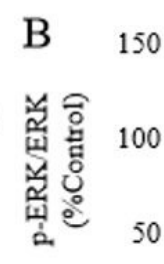

C

$54 / 46 \mathrm{kDa}$

54/46 kDa

$43 \mathrm{kDa}$

$38 \mathrm{kDa}$

$38 \mathrm{kDa}$

$43 \mathrm{kDa}$
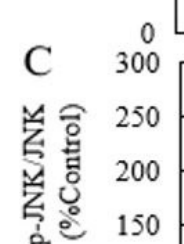

300

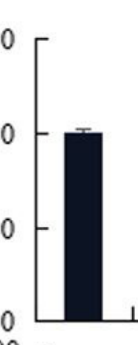

\#\#

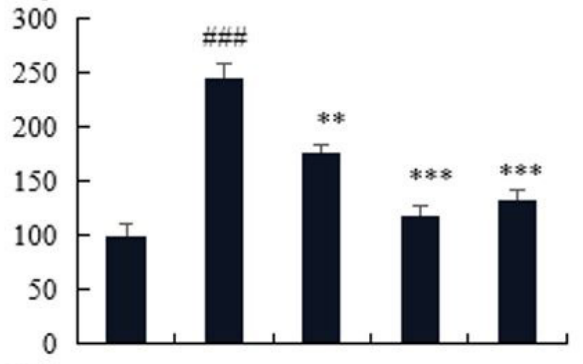

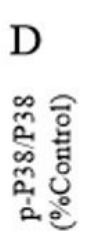

250
\#\#

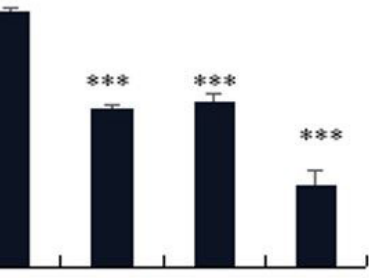

$\begin{array}{rccccc}\operatorname{LPS}(2 \mu \mathrm{g} / \mathrm{mL}) & - & + & + & + & + \\ \mathrm{HJE}(\mu \mathrm{g} / \mathrm{mL}) & - & - & 25 & 50 & - \\ \text { Luteolin }(\mu \mathrm{M}) & - & - & - & - & 30\end{array}$

Figure 5. HJE and luteolin control the MAPK signal pathways activation in microglial activation induced by LPS. $5 \times 10^{5} \mathrm{cells} / \mathrm{mL}$ of microglial cells were cultivated and disposed by HJE or luteolin (A) in advance and then stimulated with LPS lasting thirty minutes. The protein expression degrees of cell signaling kinases were discovered through western blot assays and the analysis of band densities was conducted with the assistance of Image J analysis software and normalized to the $\beta$-actin levels (B-D). Error bars represent the means $\pm S D$; ${ }^{\# \#} \mathrm{P}<.001$ versus control team; ${ }^{*} \mathrm{P}<.01$, and ${ }^{* *} \mathrm{P}<.001$ vs. only LPS group. Outcomes are representative of three independent experiments. 
TNF- $\alpha$, together with IL-6 (Figure 3). The associated molecular mechanism through which HJE and luteolin influences microglial cells will be investigated in follow-up research.

\subsection{Effect of HJE and luteolin on the Nrf2/HO-1 signaling pathway in stimulated microglial cells}

$\mathrm{Nrf2}$ as an antioxidant transcription element that fixes to gene promoters ARE, can regulate various endogenous cytoprotective genes, including encoding anti-inflammatory proteins (Ali et al., 2018). It is revealed that Nrf2 signaling pathway had the close relationship with neurodegenerative sickness (Buendia et al., 2016). Nrf2 pathway is of great value in therapeutic goal for neuroprotection (Johnson \& Johnson, 2015). If Nrf2 inducers activate Nrf2/ARE pathway, Nrf2 translocates to the nucleus and leads to its downstream goal genes like $\mathrm{HO}-1$ in the end (Zhang, 2006). It is found that HO-1 also had the wide expression in inflammatory sickness. HO-1 restrains the heme in hemoglobin into $\mathrm{CO}$, iron, and biliverdin. While biliverdin could be changed to bilirubin, which supposed to be an endogenous antioxidant (Ryter et al., 2006). Here, Nrf2 was increased in the cytosols and nucleus of HJE and luteolin-treated LPS-stimulated microglia cells (Figure 6A, 6B). Meanwhile, HJE and luteolin improved HO-1 expression in LPS-stimulated microglial cells (Figure 6C).

The Nrf2 signaling pathway was supposed to be essential in restraining neuroinflammation (Okorji et al., 2016). Nrf2 along with NF- $\mathrm{KB}$ signaling pathways mediate adverse cellular processes, resulting in either cytoprotective or pathological effects (Loboda et al., 2016). Furthermore, it was demonstrated that Nrf2 adjusts the anti-neuroinflammatory movement through directly inhibiting the NF- $\mathrm{kB}$ signaling pathway (Okorji et al., 2016). Inflammation-induced activation of BV2 cells has been shown to take place mainly via LPS-induced stimulation which in turn interacts with the NF- $\mathrm{kB}$ and Nrf2/HO-1 signaling pathways (Ding et al., 2016; Koh et al., 2011). It has been revealed that Nrf2/ HO-1 signaling pathway activation has a restrained influence on the NF- $\kappa \mathrm{B}$ pathway, while activation of above -mentioned two pathways is restrained to each other (Wang et al., 2018a). It was known that Nrf2 knockdown prompts NF- $\mathrm{KB}$ and IKK $\beta$ phosphorylation in LPS-stimulated BV2 cells, inducing improved degrees of IL-1 $\beta$, TNF- $\alpha$, and COX2 (Gozzelino et al., 2010). In addition, silencing of the Nrf2 gene is able to enhance the DNA-binding ability of NF- $\kappa \mathrm{B}$ and provoke NF- $\kappa \mathrm{B}$ signaling pathway, thereby leading to oxidative and inflammatory replies in LPS-stimulated BV2 cells (Wang et al., 2018b). Our findings suggested that HJE and luteolin promotes Nrf2 by inhibiting NF-KB phosphorylation. Furthermore, LPS-induced activation of microglial cells mainly involved the NF- $\mathrm{KB}$ along with Nrf2/ HO-1 signaling pathways, while Nrf2/HO-1 signaling pathway activation influenced restrainedly on the NF- $\kappa B$ signaling pathway. Our data suggest that these two pathways restrain to each other; however, whether the NF- $\mathrm{kB}$ along with $\mathrm{Nrf} 2 / \mathrm{HO}-1$ pathways play mutually restrictive roles in mediating the inflammatory replies of LPS-stimulated microglia warrants discovery in depth.

Furthermore, ERK1/2 was shown to mediate Nrf2 stability and subsequently activate HO-1 transcription. Moreover, it was indicated that the p38 MAPK movement negatively regulates Nrf2 stability and positively regulate $\mathrm{HO}-1$ expression, manifesting that the p38MAPK and ERK1/2 seem to aim Nrf2/HO-1 signaling pathway through various locations (Qiu et al., 2020). At the same time, MAPKs have been involved in Nrf2 phosphorylation, allowing its translocation from cytoplasm to nucleus (Sun et al., 2009). In addition, it has shown that protein kinases involved in the phosphorylation and nuclear accumulation of Nrf2 include mitogen-activated PI3K/Akt and protein kinase (MAPKs) (Joshi \& Johnson, 2012; Bryan et al., 2013). Our study suggest that the inflammatory responses of microglia are closely related to the Nrf2/HO-1, MAPK, along with AKT signaling pathways; however, we need to study of if MAPK pathway's leading role existed in LPS-stimulated SIM A9 microglia inflammatory response.
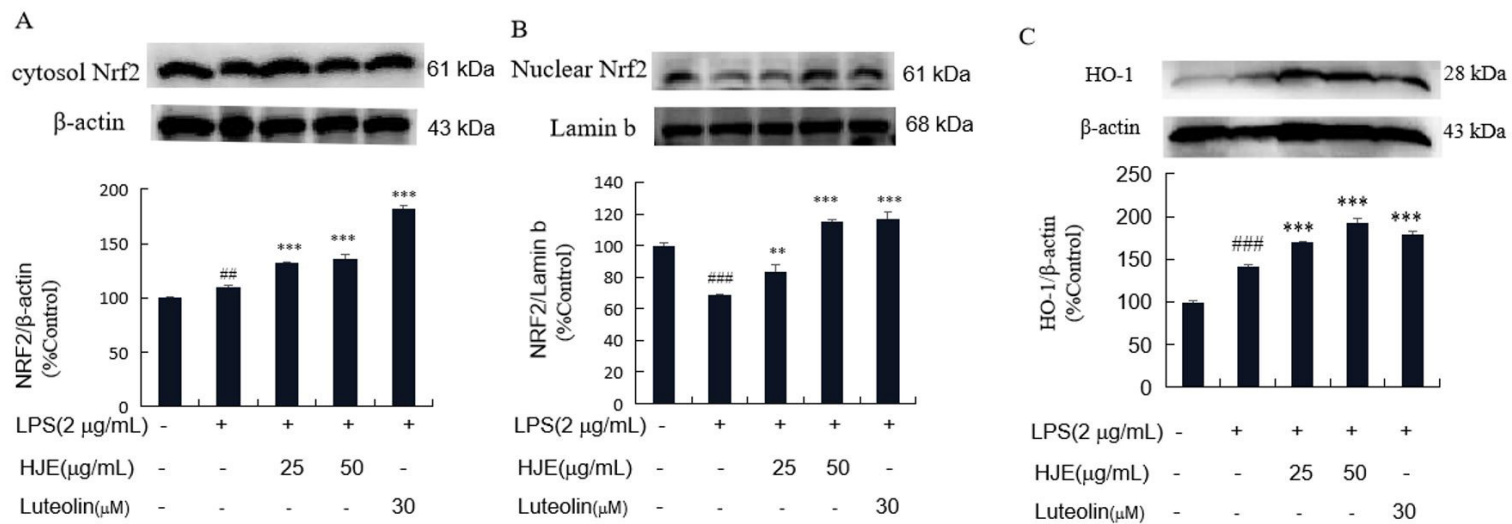

Figure 6. HJE and luteolin regulate the activation of Nrf2 signal pathways (A), increased the nuclear translocation of Nrf2 (B), and HO-1 expression levels (C) in the microglial activation induced via LPS. Microglial cells $\left(5 \times 10^{5} \mathrm{cells} / \mathrm{mL}\right)$ were cultivated and disposed by HJE or luteolin in advance for 1 hour and subsequently stimulated through LPS for half an hour. The levels of protein expression of Nrf2 in the cytosol, nuclear extract and HO-1 expression levels were discovered through western blot assay and the analysis of band densities was conducted with the assistance of ImageJ analysis software, with respect to $\beta$-actin and Lamin b. Outcomes stand for mean \pm SD. ${ }^{\# \#} \mathrm{P}<.01$, and ${ }^{\# \# \#} \mathrm{P}<.001$ versus the control team. ${ }^{* *} \mathrm{P}<.01$, and ${ }^{* *} \mathrm{P}<.001$ versus only LPS group. Outcomes from three researches of independence are symbolic. 


\section{Conclusions}

In conclusion, $\mathrm{HJE}$ and luteolin attenuated LPS-induced IL-1 $\beta$, IL-6, TNF- $\alpha$, PGE/COX2, along with $\mathrm{NO} /$ iNOS generation in SIM A9 microglial cells, which was associated with NF- $\kappa$ B and MAPK signaling pathway restrain, as well as $\mathrm{Nrf} 2 / \mathrm{HO}-1$ pathway activation. These outcomes suggesting that HJE and luteolin might represent a potential template for the development of neurological disease drugs. Nevertheless, studies investigating the mechanism underlying the anti-inflammatory effect of $\mathrm{HJE}$ and luteolin on the corresponding anti-neuroinflammatory effects in vivo experimental are also required.

\section{Conflict of interest}

The authors declare no conflict of interests.

\section{Funding}

This research was financially supported by the Ministry of Small and Medium Enterprise and Startups (MSS), Korea, under the Social Economy Innovation Growth Project (R\&D) (Project number P0013037)" supervised by the Korea Institute for Advancement of Technology.

\section{References}

Ali, T., Rehman, S. U., Shah, F. A., \& Kim, M. O. (2018). Acute dose of melatonin via Nrf2 dependently prevents acute ethanolinduced neurotoxicity in the developing rodent brain. Journal of Neuroinflammation, 15(1), 119. http://dx.doi.org/10.1186/s12974018-1157-x. PMid:29679979.

Askew, K., Li, K., Olmos-Alonso, A., Garcia-Moreno, F., Liang, Y., Richardson, P., Tipton, T., Chapman, M. A., Riecken, K., Beccari, S., Sierra, A., Molnár, Z., Cragg, M. S., Garaschuk, O., Perry, V. H., \& Gomez-Nicola, D. (2017). Coupled Proliferation and apoptosis maintain the rapid turnover of microglia in the adult brain. Cell Reports, 18(2), 391-405. http://dx.doi.org/10.1016/j.celrep.2016.12.041. PMid:28076784.

Block, M. L., \& Hong, J. S. (2005). Microglia and inflammation-mediated neurodegeneration: multiple triggers with a common mechanism. Progress in Neurobiology, 76(2), 77-98. http://dx.doi.org/10.1016/j. pneurobio.2005.06.004. PMid:16081203.

Bryan, H. K., Olayanju, A., Goldring, C. E., \& Park, B. K. (2013). The Nrf2 cell defence pathway: Keap1-dependent and-independent mechanisms of regulation. Biochemical Pharmacology, 85(6), 705717. http://dx.doi.org/10.1016/j.bcp.2012.11.016. PMid:23219527.

Buendia, I., Michalska, P., Navarro, E., Gameiro, I., Egea, J., \& Leon, R. (2016). Nrf2-ARE pathway: an emerging target against oxidative stress and neuroinflammation in neurodegenerative diseases. Pharmacology \& Therapeutics, 157, 84-104. http://dx.doi.org/10.1016/j. pharmthera.2015.11.003. PMid:26617217.

Choi, J. Y., Desta, K. T., Lee, S. J., Kim, Y. H., Shin, S. C., Kim, G. S., Lee, S. J., Shim, J. H., Hacımüftüoğlu, A., \& Abd El-Aty, A. M. (2018). LCMS/MS profiling of polyphenol-enriched leaf, stem and root extracts of Korean Humulus japonicus Siebold \& Zucc and determination of their antioxidant effects. Biomedical Chromatography, 32(5), e4171. http://dx.doi.org/10.1002/bmc.4171. PMid:29240230.

Ding, H.-Y., Wu, P.-S., \& Wu, M.-J. (2016). Cleome rutidosperma and Euphorbia thymifolia suppress inflammatory response via upregulation of phase II enzymes and modulation of NF- $\kappa \mathrm{B}$ and JNK activation in LPS-stimulated BV2 microglia. International
Journal of Molecular Sciences, 17(9), 1420. http://dx.doi.org/10.3390/ ijms17091420. PMid:27618898.

Fellner, A., Barhum, Y., Angel, A., Perets, N., Steiner, I., Offen, D., \& Lev, N. (2017). Toll-like receptor-4 inhibitor TAK-242 attenuates motor dysfunction and spinal cord pathology in an amyotrophic lateral sclerosis mouse model. International Journal of Molecular Sciences, 18(8), 1666. http://dx.doi.org/10.3390/ijms18081666. PMid:28763002.

Gozzelino, R., Jeney, V., \& Soares, M. P. (2010). Mechanisms of cell protection by heme oxygenase-1. Annual Review of Pharmacology and Toxicology, 50(1), 323-354. http://dx.doi.org/10.1146/annurev. pharmtox.010909.105600. PMid:20055707.

Hoeffel, G., Chen, J., Lavin, Y., Low, D., Almeida, F. F., See, P., Beaudin, A. E., Lum, J., Low, I., Forsberg, E. C., Poidinger, M., Zolezzi, F., Larbi, A., Ng, L. G., Chan, J. K., Greter, M., Becher, B., Samokhvalov, I. M., Merad, M., \& Ginhoux, F. (2015). C-Myb+ erythro-myeloid progenitor-derived fetal monocytes give rise to adult tissue-resident macrophages. Immunity, 42(4), 665-678. http://dx.doi.org/10.1016/j. immuni.2015.03.011. PMid:25902481.

Johnson, D. A., \& Johnson, J. A. (2015). Nrf2--a therapeutic target for the treatment of neurodegenerative diseases. Free Radical Biology and Medicine, 88(Pt B), 253-267. https://doi.org/10.1016/j. freeradbiomed.2015.07.147.

Joshi, G., \& Johnson, J. A. (2012). The Nrf2-ARE pathway: a valuable therapeutic target for the treatment of neurodegenerative diseases. Recent Patents on CNS Drug Discovery, 7(3), 218-229. http://dx.doi. org/10.2174/157488912803252023. PMid:22742419.

Koh, K., Kim, J., Jang, Y. J., Yoon, K., Cha, Y., Lee, H. J., \& Kim, J. (2011). Transcription factor Nrf2 suppresses LPS-induced hyperactivation of BV-2 microglial cells. Journal of Neuroimmunology, 233(1-2), 160-167. http://dx.doi.org/10.1016/j.jneuroim.2011.01.004. PMid:21349591.

Lee, H. J., Dhodary, B., Lee, J. Y., An, J.-P., Ryu, Y.-K., Kim, K.-S., Lee, C. H., \& Oh, W. K. (2019). Dereplication of Components coupled with HPLC-qTOF-MS in the active fraction of Humulus japonicus and it's protective effects against Parkinson's Disease Mouse Model. Molecules (Basel, Switzerland), 24(7), 1435. http://dx.doi.org/10.3390/ molecules24071435. PMid:30979037.

Liu, T., Zhang, L., Joo, D., \& Sun, S.-C. (2017). NF- $\kappa B$ signaling in inflammation. Signal Transduction and Targeted Therapy, 2(1), 1-9. http://dx.doi.org/10.1038/sigtrans.2017.23. PMid:29158945.

Loboda, A., Damulewicz, M., Pyza, E., Jozkowicz, A., \& Dulak, J. (2016). Role of Nrf2/HO-1 system in development, oxidative stress response and diseases: an evolutionarily conserved mechanism. Cellular and Molecular Life Sciences, 73(17), 3221-3247. http://dx.doi.org/10.1007/ s00018-016-2223-0. PMid:27100828.

Miyagishi, H., Kosuge, Y., Yoneoka, Y., Ozone, M., Endo, M., Osada, N., Ishige, K., Kusama-Eguchi, K., \& Ito, Y. (2013). Prostaglandin E2-induced cell death is mediated by activation of EP2 receptors in motor neuron-like NSC-34 cells. Journal of Pharmacological Sciences, 121(4), 347-350. http://dx.doi.org/10.1254/jphs.12274SC. PMid:23514786.

Okorji, U. P., Velagapudi, R., El-Bakoush, A., Fiebich, B. L., \& Olajide, O. A. (2016). Antimalarial drug artemether inhibits neuroinflammation in BV2 microglia through Nrf2-dependent mechanisms. Molecular Neurobiology, 53(9), 6426-6443. http://dx.doi.org/10.1007/s12035015-9543-1. PMid:26607631.

Onasanwo, S. A., Velagapudi, R., El-Bakoush, A., \& Olajide, O. A. (2016). Inhibition of neuroinflammation in BV2 microglia by the biflavonoid kolaviron is dependent on the Nrf2/ARE antioxidant protective mechanism. Molecular and Cellular Biochemistry, 414(1-2), 23-36. http://dx.doi.org/10.1007/s11010-016-2655-8. PMid:26838169. 
Park, S. W., Woo, C. J., Chung, S. K., \& Chung, K. T. (1994). Antimicrobial and antioxidative activities of solvent fraction from Humulus japonicus. Korean Journal of Food Science Technology, 26(4), 464-470.

Park, T. S., Ryu, Y. K., Park, H. Y., Kim, J. Y., Go, J., Noh, J. R., Kim, Y. H., Hwang, J. H., Choi, D. H., Oh, W. K., Lee, C. H., \& Kim, K. S. (2017). Humulus japonicus inhibits the progression of Alzheimer's disease in a APP/PS1 transgenic mouse model. International Journal of Molecular Medicine, 39(1), 21-30. http://dx.doi.org/10.3892/ ijmm.2016.2804. PMid:28004107.

Perry, V. H., Nicoll, J. A., \& Holmes, C. (2010). Microglia in neurodegenerative disease. Nature Reviews. Neurology, 6(4), 193201. http://dx.doi.org/10.1038/nrneurol.2010.17. PMid:20234358.

Qiu, Z., Lu, P., Wang, K., Zhao, X., Li, Q., Wen, J., Zhang, H., Li, R., Wei, H., Lv, Y., Zhang, S., \& Zhang, P. (2020). Dexmedetomidine inhibits neuroinflammation by altering microglial M1/M2 polarization through MAPK/ERK pathway. Neurochemical Research, 45(2), 345353. http://dx.doi.org/10.1007/s11064-019-02922-1. PMid:31823113.

Ryter, S. W., Alam, J. \& Choi, A. M. (2006). Heme oxygenase-1/carbon monoxide: from basic science to therapeutic applications. Physiological Reviews, 86(2), 583-650. http://dx.doi.org/10.1152/physrev.00011.2005.

Ryu, Y. K., Kang, Y., Go, J., Park, H. Y., Noh, J. R., Kim, Y. H., Hwang, J. H., Choi, D. H., Han, S. S., Oh, W. K., Lee, C. H., \& Kim, K. S. (2017). Humulus japonicus Prevents Dopaminergic Neuron Death in 6-Hydroxydopamine-Induced Models of Parkinson's Disease. Journal of Medicinal Food, 20(2), 116-123. http://dx.doi.org/10.1089/ jmf.2016.3851. PMid:28146406.

Stephenson, J., Nutma, E., van der Valk, P., \& Amor, S. (2018). Inflammation in CNS neurodegenerative diseases. Immunology, 154(2), 204-219. http://dx.doi.org/10.1111/imm.12922. PMid:29513402.

Subedi, L., Kwon, O. W., Pak, C., Lee, G., Lee, K., Kim, H., \& Kim, S. Y. (2017). N, N-disubstituted azines attenuate LPS-mediated neuroinflammation in microglia and neuronal apoptosis via inhibiting MAPK signaling pathways. BMC Neuroscience, 18(1), 82. http://dx.doi.org/10.1186/s12868-017-0399-3. PMid:29281977.

Sun, Z., Huang, Z., \& Zhang, D. D. (2009). Phosphorylation of Nrf2 at multiple sites by MAP kinases has a limited contribution in modulating the Nrf2-dependent antioxidant response. PLoS One, 4(8), e6588. http://dx.doi.org/10.1371/journal.pone.0006588. PMid:19668370.
Sung, B., Chung, J. W., Bae, H. R., Choi, J. S., Kim, C. M., \& Kim, N. D. (2015). Humulus japonicus extract exhibits antioxidative and anti-aging effects via modulation of the AMPK-SIRT1 pathway. Experimental and Therapeutic Medicine, 9(5), 1819-1826. https:// doi.org/10.3892/etm.2015.2302.

Wang, X., Gai, Y.-N., Li, B.-B., \& Huang, L.-L. (2018a). Andalucin from Artemisia lannta suppresses the neuroinflammation via the promotion of Nrf2-mediated HO-1 levels by blocking the p65p300 interaction in LPS-activated BV2 microglia. Phytomedicine, 51, 226-232. http://dx.doi.org/10.1016/j.phymed.2018.06.014. PMid:30466621.

Wang, M., Wang, K., Gao, X., Zhao, K., Chen, H., \& Xu, M. (2018b). Anti-inflammatory effects of isoalantolactone on LPS-stimulated BV2 microglia cells through activating GSK-3 $\beta$-Nrf2 signaling pathway. International Immunopharmacology, 65, 323-327. http:// dx.doi.org/10.1016/j.intimp.2018.10.008. PMid:30343259.

Xu, J., Yuan, C., Wang, G., Luo, J., Ma, H., Xu, L., Mu, Y., Li, Y., Seeram, N. P., Huang, X., \& Li, L. (2018). Urolithins attenuate LPS-induced neuroinflammation in BV2 Microglia via MAPK, Akt, and NF- $\kappa B$ signaling pathways. Journal of Agricultural and Food Chemistry, 66(3), 571-580. http://dx.doi.org/10.1021/acs.jafc.7b03285. PMid:29336147.

Yang, S., Chu, S., Ai, Q., Zhang, Z., Gao, Y., Lin, M., Liu, Y., Hu, Y., Li, X., Peng, Y., Pan, Y., He, Q., \& Chen, N. (2020). Anti-inflammatory effects of higenamine (Hig) on LPS-activated mouse microglia (BV2) through NF- $\kappa \mathrm{B}$ and $\mathrm{Nrf} 2 / \mathrm{HO}-1$ signaling pathways. International Immunopharmacology, 85, 106629. http://dx.doi.org/10.1016/j. intimp.2020.106629. PMid:32535536.

Yu, B. C., Yang, M. C., Lee, K. H., Kim, K. H., Choi, S. U., \& Lee, K. R. (2007). Two new phenolic constituents of Humulus japonicus and their cytotoxicity test in vitro. Archives of Pharmacal Research, 30(11), 1471-1475. http://dx.doi.org/10.1007/BF02977373. PMid:18087817.

Yuste, J. E., Tarragon, E., Campuzano, C. M., \& Ros-Bernal, F. (2015). Implications of glial nitric oxide in neurodegenerative diseases. Frontiers in Cellular Neuroscience, 9, 322. http://dx.doi.org/10.3389/ fncel.2015.00322. PMid:26347610.

Zhang, D. D. (2006). Mechanistic Studies of the Nrf2-Keap1 Signaling Pathway. Drug Metabolism Reviews, 38(4), 769-789. http://dx.doi. org/10.1080/03602530600971974. PMid:17145701. 